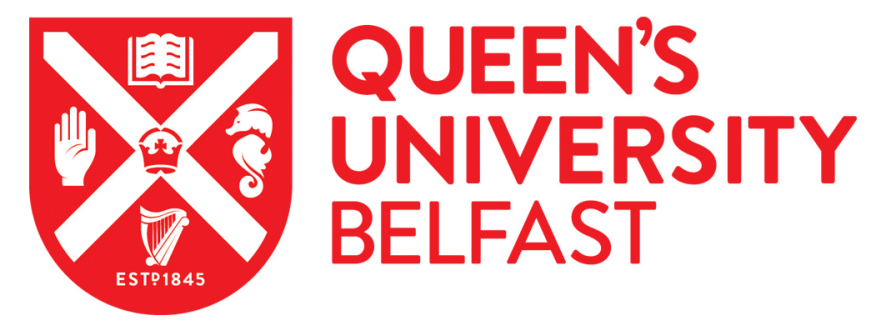

\title{
Hand arthritis in systemic lupus erythematosus: an ultrasound pictorial essay.
}

Bell, A., Wright, S. A., Filippucci, E. F., Grassi, W., Grey, A., \& Bell, A. L. (2006). Hand arthritis in systemic lupus erythematosus: an ultrasound pictorial essay. Lupus, 15(8)(8), 501-506.

https://doi.org/10.1191/0961203306lu2340oa

\section{Published in:}

Lupus

Queen's University Belfast - Research Portal:

Link to publication record in Queen's University Belfast Research Portal

\section{General rights}

Copyright for the publications made accessible via the Queen's University Belfast Research Portal is retained by the author(s) and / or other copyright owners and it is a condition of accessing these publications that users recognise and abide by the legal requirements associated with these rights.

Take down policy

The Research Portal is Queen's institutional repository that provides access to Queen's research output. Every effort has been made to ensure that content in the Research Portal does not infringe any person's rights, or applicable UK laws. If you discover content in the Research Portal that you believe breaches copyright or violates any law, please contact openaccess@qub.ac.uk. 
Hand Arthritis in Systemic Lupus Erythematosus: An Ultrasound Pictorial Essay

S Wright, E Filippucci, W Grassi, A Grey and A Bell

Lupus 2006; 15; 501

DOI: 10.1191/0961203306lu2340oa

The online version of this article can be found at:

http://lup.sagepub.com/cgi/content/abstract/15/8/501

\author{
Published by: \\ (3) SAGE Publications \\ http://www.sagepublications.com
}

Additional services and information for Lupus can be found at:

Email Alerts: http://lup.sagepub.com/cgi/alerts

Subscriptions: http://lup.sagepub.com/subscriptions

Reprints: http://www.sagepub.com/journalsReprints.nav

Permissions: http://www.sagepub.com/journalsPermissions.nav

Citations (this article cites 18 articles hosted on the

SAGE Journals Online and HighWire Press platforms):

http://lup.sagepub.com/cgi/content/abstract/15/8/501\#BIBL 


\title{
Hand arthritis in systemic lupus erythematosus: an ultrasound pictorial essay
}

\author{
S Wright ${ }^{1 *}$, E Filippucci $^{2}, \mathrm{~W}$ Grassi $^{2}$, A Grey $^{3}$ and A Bell ${ }^{1}$ \\ ${ }^{1}$ Queens University Lupus Research Group, Musgrave Park Hospital, Stockmans Lane, Belfast, Northern Ireland; \\ ${ }^{2}$ Università degli Studi di Ancona, Scuola di Specializzazione in Reumatologia, Ospedali di Jesi, Italy; and \\ ${ }^{3}$ Department of Radiology, Musgrave Park Hospital, Stockmans Lane, Belfast, Northern Ireland
}

\begin{abstract}
A small minority of systemic lupus erythematosus (SLE) patients may develop a deforming arthritis, typically with a non-erosive (Jaccoud's) pattern, although erosive features indistinguishable from rheumatoid arthritis may also occur. High-resolution ultrasonography (HRUS) allows detailed 'real time' imaging of joint and tendon morphostructural changes involving the hand in patients with several rheumatic diseases. The main aim of this pictorial essay is to provide the first descriptive HRUS and power Doppler (PD) findings of joint and tendon involvement of the hand and wrist in patients with SLE arthritis. Seventeen patients with SLE and hand involvement were examined. HRUS of the wrist, 2nd and 3rd MCP joints, 3rd PIP joint and 2nd, 3rd and 4th finger flexor tendons were studied in the dominant hand for each patient. Sixteen $(94 \%)$ patients had joint effusion or synovial hypertrophy in the wrist. Twelve (71\%) patients had joint effusion or synovial hypertrophy in 2nd or 3rd MCPJs. Eight $(47 \%)$ patients had erosion at 2nd or 3rd MCPJs. In three cases erosions were not present radiologically. Eleven $(65 \%)$ patients had evidence of tenosynovitis. In SLE, HRUS with PD detects a high prevalence of inflammatory pathology in the tendons and synovium of the hand and wrist, and a high prevalence of MCP joint erosions. HRUS offers a sensitive, real-time and readily repeatable assessment of soft-tissue, inflammatory and bony changes in SLE hands. Lupus (2006) 15, 501-506.
\end{abstract}

Key words: arthritis; musculoskeletal ultrasound; SLE

\section{Introduction}

Joint involvement in systemic lupus erythematosus (SLE) is often characterized by arthralgia without objective clinical features of joint synovitis, and in many cases is transient, migratory and reversible. ${ }^{1}$ In patients with more perisistent hand involvement there may be clinical tenosynovitis and joint swelling. A small minority may develop a deforming, typically non-erosive pattern known as Jaccoud's arthritis, a term first applied in 1869 to describe deforming arthritis in cases of rheumatic fever. Ulnar deviation at the metacarpophalangeal (MCP) joints in the absence of radiological erosion has been used to define Jaccoud's arthritis, ${ }^{2}$ although a more precise set of clinical classification criteria, the Jaccoud's arthropathy index (JAI) has been developed. ${ }^{3}$ Some SLE patients (many of whom are seropositive for rheumatoid factor) may also develop a deforming arthritis with erosive features indistinguishable from rheumatoid arthritis

*Correspondence: Dr Stephen Wright, Department of Rheumatology, Musgrave Park Hospital, Stockmans Lane, Belfast, BT9, Northern Ireland. E-mail: s.wright@qub.ac.uk

Received 20 February 2006; accepted 19 April 2006 (the 'rhupus' hand). A recent study of hand arthritis in SLE describes three typical patterns in addition to nondeforming arthropathy; Jaccoud's arthropathy, erosive arthropathy and mild deforming arthropathy. ${ }^{4}$

Radiological features in lupus hand arthritis includes scapholunate dissociation, joint space narrowing, cystic change and palmar/ulnar subluxation in the wrist. In the fingers, MCP hook erosions, MCP subluxation and cystic change are commonest, but overt rheumatoid marginal erosion pattern is rare. ${ }^{5} \mathrm{~A}$ recent magnetic resonance imaging (MRI) study ${ }^{6}$ demonstrated significant soft tissue and bony abnormalities in the hands of patients with SLE.

Musculoskeletal high resolution ultrasound (HRUS) allows detailed 'real time' imaging of joints, and is more readily accessible at lower cost than MRI. ${ }^{7,8}$ The addition of power Doppler (PD) provides a sensitive assessment of soft tissue hyperaemia. Despite HRUS providing exquisite details of soft tissue involvement in several rheumatic diseases, to date there are no studies showing its potential in depicting joint and tendon pathology in patients with SLE.

To the best of our knowledge there is only one paper focusing on the potential role of musculoskeletal 
ultrasonography in patients with SLE. ${ }^{9}$ Iagnocco et al. evaluated the wrist in 26 SLE patients. Although a high prevalence of wrist joint synovitis (42\% of patients) and tenosynovitis (44\% of patients) was found, only one patient had evidence of erosions at the wrist. Furthermore very little attention was paid on providing representative sonographic pictures.

The main aim of this pictorial essay is to provide the first descriptive HRUS and power Doppler findings of joint and tendon involvement of both the hand and wrist in patients with SLE arthritis.

\section{Methods}

Seventeen consecutive patients fulfilling the ACR criteria $^{10}$ for SLE and presenting with hand involvement (including those with classical Jaccoud's arthritis, mild deforming arthropathy and symptomatic hands) were examined. These patients were recruited from Rheumatology out-patient clinics in Belfast. Clinical examination of the hands was recorded as the Jaccoud's arthropathy index $(\mathrm{JAI})^{3}$ and as a hand deformity score. The JAI gives a composite score of both hands whereas in the hand deformity score, a point was assigned for each deformity (ulnar drift $>20^{\circ}$, swan neck, Boutonniere or Z-deformity) in the dominant hand only. Disease activity was assessed using the SLAM (Systemic Lupus Activity Measure) and organ damage was assessed using the American College of Rheumatology/Systemic Lupus International Collaborating Clinics (ACR/SLICC) score. ${ }^{11}$ All HRUS scans were undertaken using a Siemens Sonoline Antares with 13-5 MHz linear array transducer by two experienced investigators. The two sonographers independently scanned each patient and recorded their findings on a standardized proforma and saved all of their HRUS findings digitally for future reference. At the end of the whole study the two sonographers compared their findings and reviewed the digitized images to reach a consensus. Agreement between the two sonographers was tested using the Cohen-kappa (linear weights). The interobserver agreement between the two sonographers was $\kappa=0.85$ for HRUS erosions and $\kappa=0.78$ for HRUS soft tissue pathology. The wrist, 2nd and 3rd MCP joints, 3rd PIP joint and 2nd, 3rd and 4th finger flexor tendons were studied in the dominant hand (all patients had dominant hand involvement) for each patient using a multiplanar scanning technique. These anatomical sites were chosen, as they are relatively easily evaluated with HRUS and have provided representative pathological changes in other diseases with hand involvement. ${ }^{12,13}$ Dynamic examination was particularly helpful for the assessment of tendon echotexture during flexion-extension movements of the fingers. B-mode examination was carried out setting the machine in order to obtain the widest spectrum of grey tones. In order to standardise power Doppler examination, US equipment was set according to the indications provided by Rubin et al. ${ }^{14}$ Evidence of effusion, synovial hypertrophy, power Doppler signal, and bone erosion using OMERACT preliminary definitions ${ }^{15}$ were recorded for each site. All patients had a standard PA hand X-ray performed on the same day as the HRUS images were acquired and reported by the same radiologist.

\section{Results}

Seventeen patients (16 female) underwent HRUS of their dominant hand. Table 1 highlights the main clinical features of the patients. The mean number of ACR criteria $^{10}$ met by the patients was 6.4 . From Table 2 it can be seen that all patients were positive for antinuclear antibody and had arthritis. Thirteen (76\%) of patients had immunological involvement with 10 patients having anti-dsDNA antibody, three patients with anti-Ro antibody, two patients with anti-RNP antibody and one patient with anti-La antibody. Only one patient was weakly positive for rheumatoid factor with a titre of 29 (laboratory reference range $<20$ ).

Table 1 Clinical features of SLE patients $(n=17)$

\begin{tabular}{lc}
\hline Clinical feature & Median (range) \\
\hline Sex & 16 female; 1 male \\
Age (years) & $37.6(23-58)$ \\
Disease duration (years) & $13(5-21)$ \\
Number of ACR criteria & $6.1(4-8)$ \\
ESR (mm hour $\left.{ }^{-1}\right)$ & $24.5(6-109)$ \\
CRP (mg L $\left.{ }^{-1}\right)$ & $15.0(4-90)$ \\
SLAM & $7.1(2-16)$ \\
SLICC & $2.1(0-7)$ \\
Jaccouds arthropathy index & $5.7(2-10)$ \\
Hand deformity score & $4.8(1-8)$ \\
\hline
\end{tabular}

Table 2 ACR criteria ${ }^{10}$ of patients

\begin{tabular}{lc}
\hline ACR criteria & Number of patients (\%) \\
\hline Malar rash & $10(59 \%)$ \\
Discoid rash & $5(29 \%)$ \\
Photosensitivity & $13(76 \%)$ \\
Oral ulcers & $13(76 \%)$ \\
Arthritis & $17(100 \%)$ \\
Serositis & $4(24 \%)$ \\
Renal involvement & $3(18 \%)$ \\
Neurological involvement & $3(18 \%)$ \\
Haematological involvement & $15(88 \%)$ \\
Immunological involvement & $13(76 \%)$ \\
Anti-nuclear antibody & $17(100 \%)$ \\
\hline
\end{tabular}




\section{Wrist}

Sixteen out of 17 (94\%) patients showed either joint effusion or synovial hypertrophy in their dominant wrist. Fourteen of these 16 patients also had evidence of intraarticular PD signal (Figure 1).

\section{MCP joints}

Twelve out of 17 (71\%) patients had evidence of joint effusion or synovial hypertrophy in 2nd or 3rd MCP joints and six patients had PD signal at these sites (Figures 2 and 3). In eight out of 17 (47\%) patients, HRUS examination detected erosion at 2nd or 3rd MCP joints (PD signal was detected inside two bone erosions) (Figures 4 and 5). In three of these patients hand X-ray showed no erosion. We divided the patients

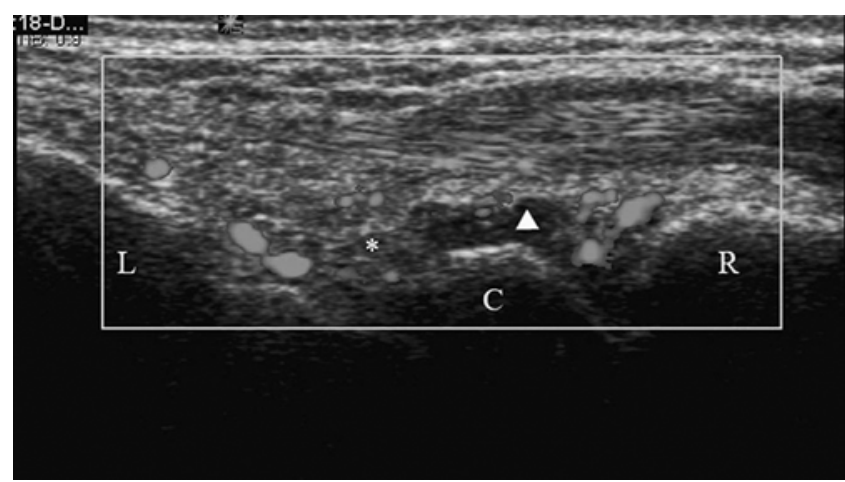

Figure 1 34-year old female with 11 year history of SLE. Longitudinal dorsal scan of the wrist showing synovial hypertrophy, joint effusion and power Doppler signal. $\mathrm{R}=$ radius; $\mathrm{L}=$ lunate; $\mathrm{C}=$ capitate; $*=$ synovial hypertrophy; white triangle $=$ synovial fluid

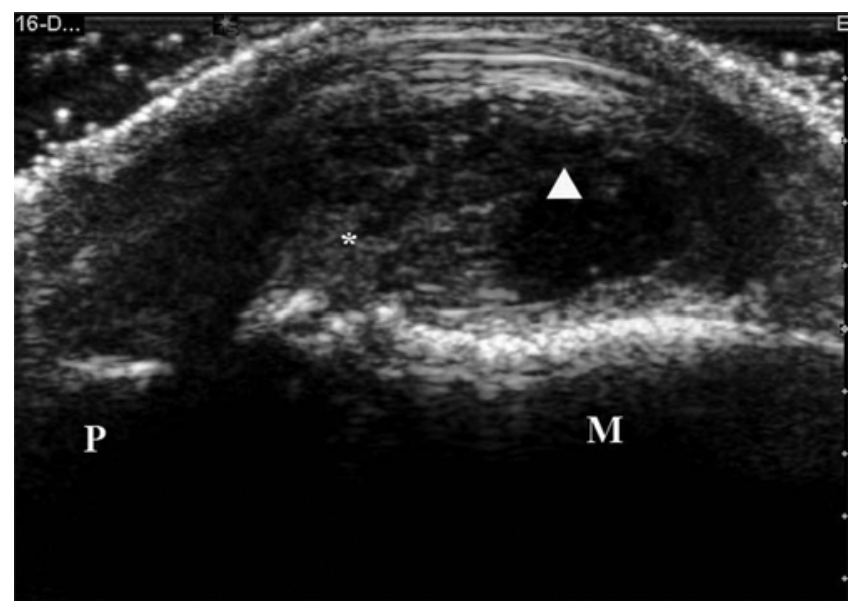

Figure 2 36-year old female with 16 year history of SLE. Longitudinal dorsal scan of 2 nd MCP joint showing marked joint cavity widening with synovial hypertrophy and joint effusion. $\mathrm{M}=$ metacarpal bone; $\mathrm{P}=$ proximal phalanx; ${ }^{*}=$ synovial hypertrophy; white triangle $=$ synovial fluid.

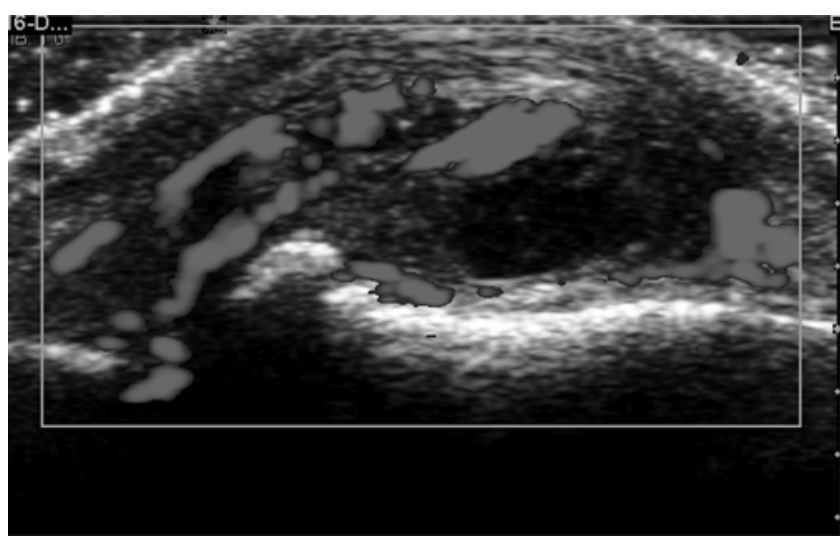

Figure 3 36-year old female with 16 year history of SLE. Longitudinal dorsal scan of 2nd MCP joint (same as in Figure 2) showing marked intraarticular PD signal.

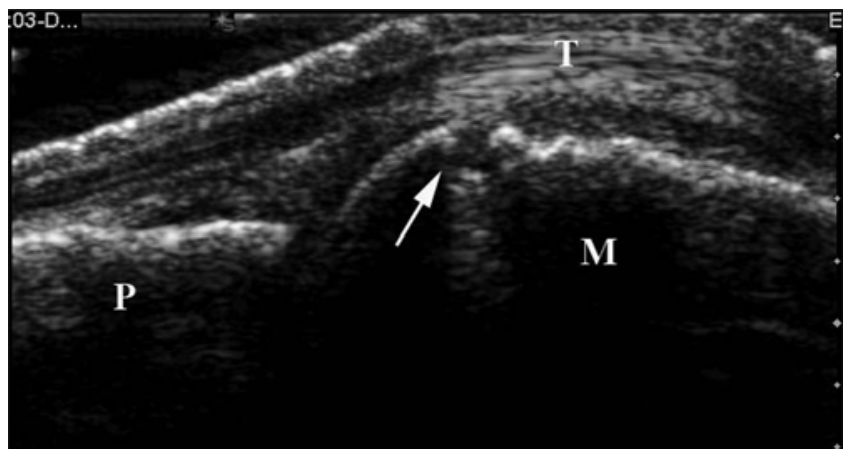

Figure 4 42-year old female with 21 year history of SLE. Longitudinal scan of 2nd MCP joint showing bone erosion (the maximum distance between the free edges of the bone erosion was $1.9 \mathrm{~mm}) . \mathrm{M}=$ metacarpal bone; $\mathrm{P}=$ proximal phalanx; white arrow $=$ bone erosion; $\mathrm{T}=$ finger extensor tendon

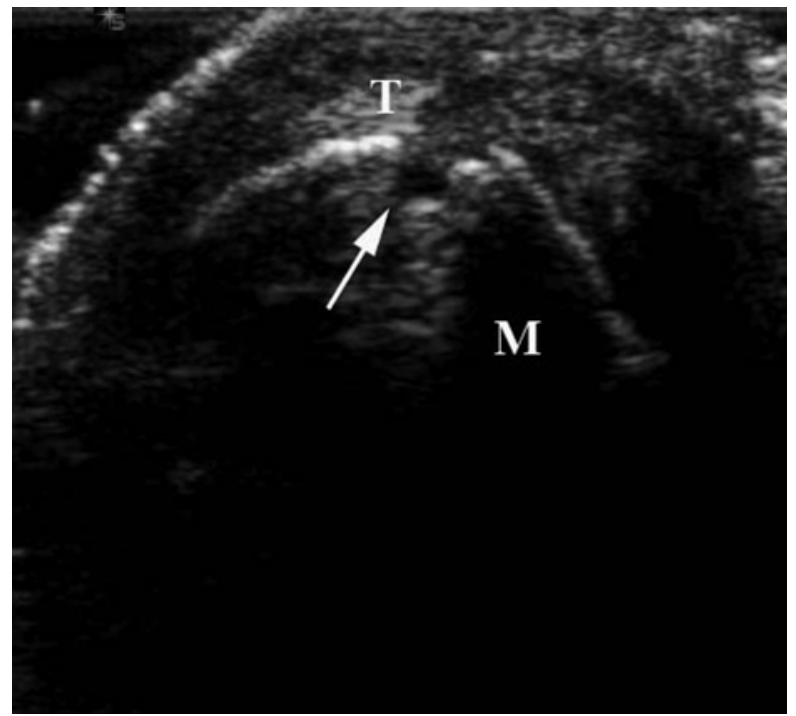

Figure 5 42-year old female with 21 year history of SLE. Transverse dorsal scan of 2nd MCP joint (same as Figure 4) showing bone erosion (the maximum distance between the free edges of the bone erosion was $2.3 \mathrm{~mm}$ ). $\mathrm{M}=$ metacarpal bone; white arrow $=$ bone erosion; $\mathrm{T}=$ finger extensor tendon 
Ultrasound in SLE arthritis S Wright et al.

504

Table 3 Clinical associations with HRUS detected erosion of 2nd/3rd MCP joints

\begin{tabular}{lcl}
\hline & 2nd/3rd MCP erosion & No erosion \\
\hline Raynauds $n(\%)$ & $4(50 \%)$ & $4(40 \%)$ \\
Antiphospholipid Ab & 0 & 0 \\
Rheumatoid factor & $1(13 \%)$ & 0 \\
Jaccoud's score & $6.5(2-10)$ & $2(2-7)$ \\
Hand deformity score & $4.5(3-8)$ & $4(3-7)$ \\
SLAM & $2(2-7)$ & $9(7-14)$ \\
SLICC & $1(0-2)$ & $4(1-7)$ \\
\hline
\end{tabular}

Results are expressed as median (range) unless specified.

into those with HRUS detected erosion and those without and Table 3 highlights the clinical associations.

\section{Tendons}

In $11(65 \%)$ out of 17 patients HRUS examination detected either tendon sheath effusion or synovial hypertrophy at 2 nd, 3rd or 4 th finger flexor tendons
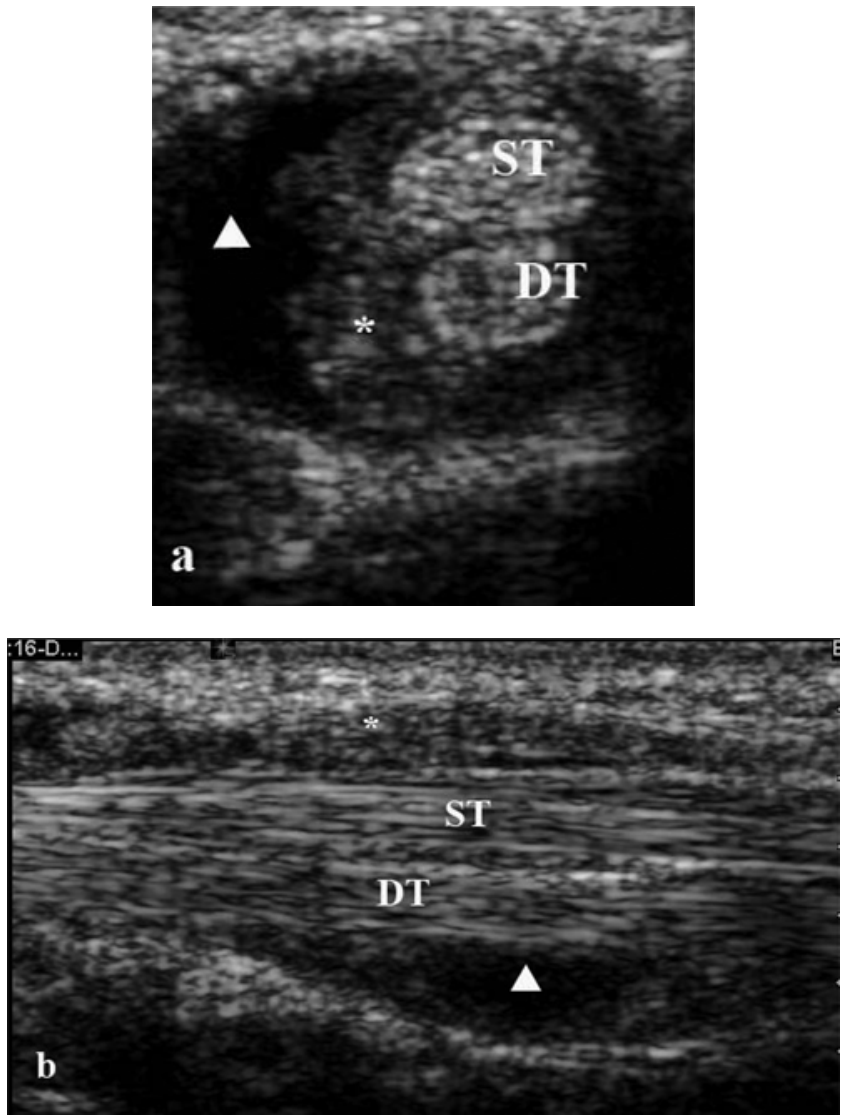

Figure 6 36-year old female with 16 year history of SLE. Transverse and longitudinal volar scans of 2nd finger flexor tendons showing obvious tenosynovitis with synovial hypertrophy and effusion. $\mathrm{a}=$ transverse $\mathrm{scan} ; \mathrm{b}=$ longitudinal scan; ST = superficial flexor tendon; DT = deep flexor tendon; $*$ = synovial hypertrophy; white triangle $=$ synovial fluid.
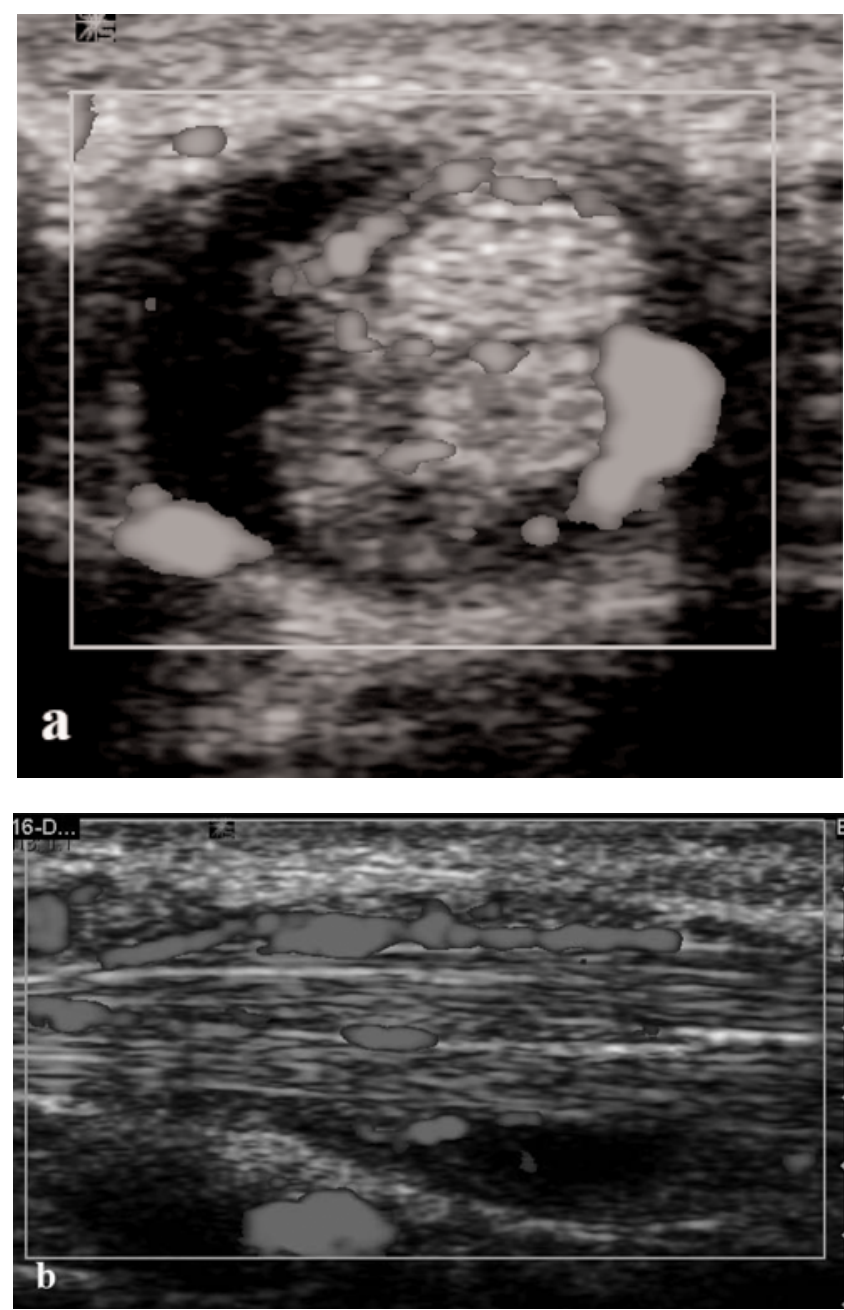

Figure 7 36-year old female with 16 year history of SLE. Transverse and longitudinal scan of 2nd finger flexor tendons (same as Figure 6) showing marked PD signal. $\mathrm{a}=$ transverse scan; $b=$ longitudinal scan.

(Figure 6a, b) and in four of these patients there was evidence of PD signal in the synovial tissue within the tendon sheath (Figure $7 \mathrm{a}, \mathrm{b}$ ). In one patient HRUS detected flexor tendon rupture (Figures 8 and 9).

\section{Discussion}

This pictorial essay provides the first HRUS evidence of a subset of SLE patients with joint and/or tendon pathology (synovitis, bone erosions, tenosynovitis and tendon rupture) similar to that detectable in patients with rheumatoid arthritis.

Our findings provide further evidence that HRUS is a safe, non-invasive imaging modality allowing detailed imaging of peri and intra-articular soft tissues. Such high quality imaging can change the way the rheumatologist approaches SLE patients in both 

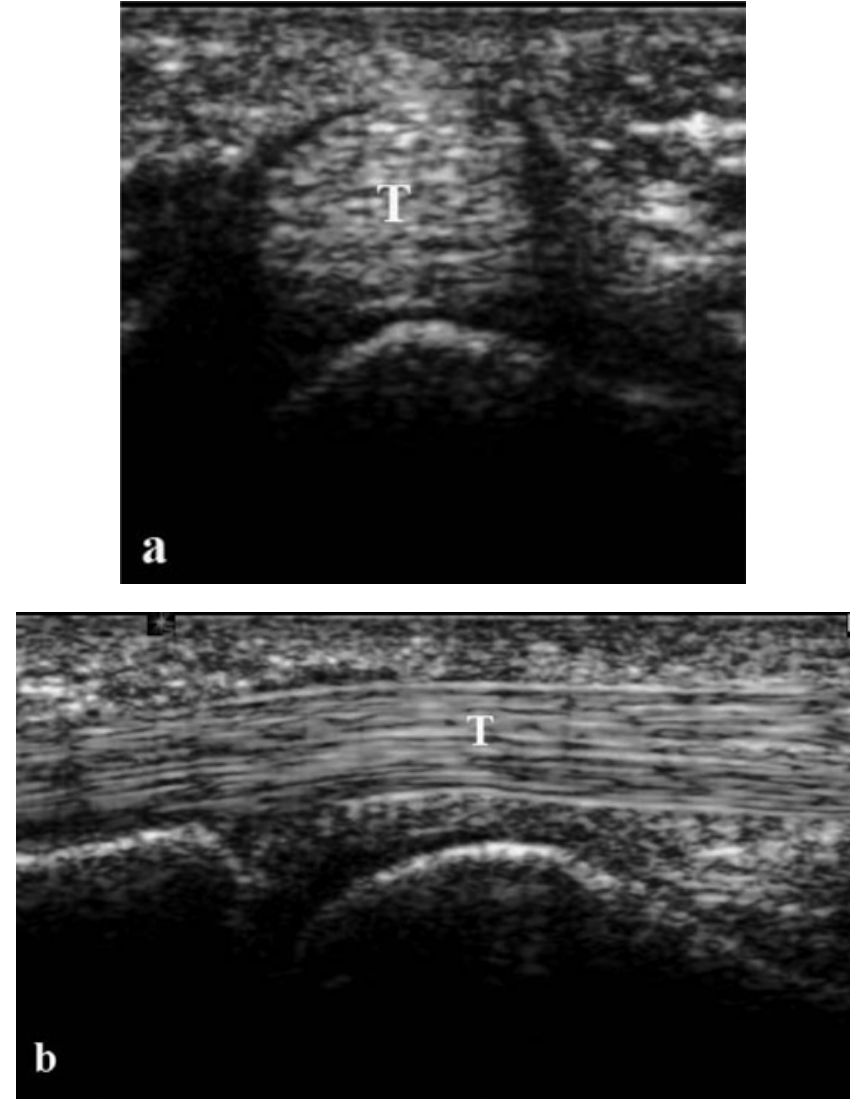

Figure 8 24-year old female with seven year history of SLE. Transverse (a) and longitudinal (b) scan of 2nd finger flexor tendon (T) showing normal morphology.

research and clinical fields. HRUS features have the potential to provide further understanding of different pathophysiological pathways in patients with SLE. Moreover, their availability in the setting of the daily clinical practice can help to choose the most appropriate treatment and subsequently monitor soft tissue changes induced by the therapy.

Although not the main aim of this pictorial study, we found an unexpected high prevalence of joint and tendon pathology in SLE patients with clinically involved hands. This result is consistent with the data reported in studies assessing HRUS in patients with rheumatoid arthritis, showing the high sensitivity of HRUS in revealing pathological findings not detected clinically or by x-ray. ${ }^{16-19}$ Moreover, in the study by Ostendorf et al. using MRI to evaluate Jaccoud's arthropathy in 14 patients with SLE, they found a similar high prevalence of tendon pathology and joint disease. Out of the 14 patients, 10 had either oedematous or proliferative tenosynovitis and eight had bony erosions with conventional $\mathrm{x}$-ray missing these erosions in two out of the eight patients. In a previous study of unselected SLE cases the prevalence of erosions was found to be less than in our study of SLE patients with
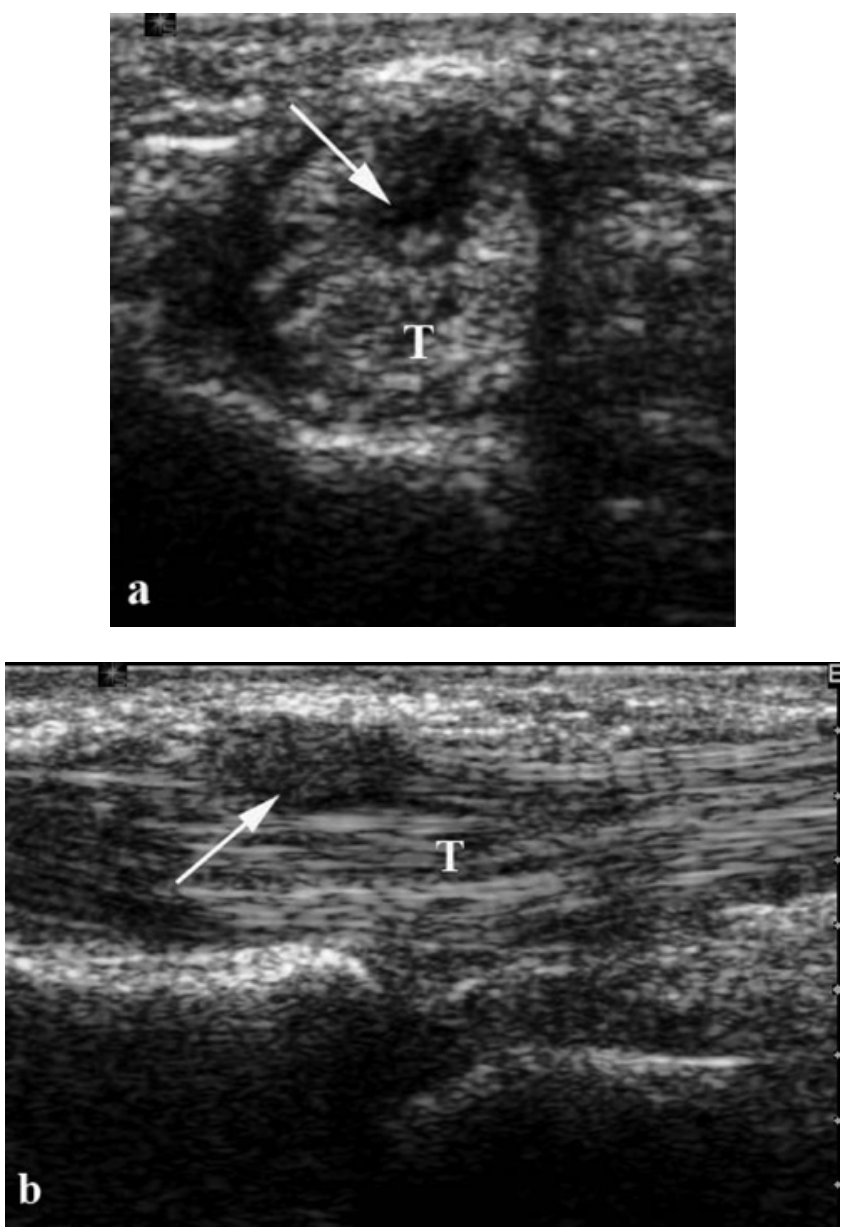

Figure 9 24-year old female with seven year history of SLE. Transverse (a) and longitudinal (b) scans of 3rd finger flexor tendon (T) (same patient as Figure 8) showing superficial tendon rupture with synovial hypertrophy. White arrow $=$ superficial flexor tendon rupture with synovial hypertrophy.

hand involvement. ${ }^{20}$ Further large prospective studies combining imaging modalities are required to help define the prevalence of erosions in lupus. From the clinical associations (Table 3), it would seem there is a trend towards a higher JAI score indicating the possibility of erosive disease. Both SLAM and SLICC scores would appear to be unhelpful in this regard, although the small sample size does not allow us to draw firm conclusions at this stage.

This is the first descriptive study establishing HRUS changes that can be found in SLE patients with hand involvement and provides a foundation for future prospective studies designed to address specific issues. Further work is required to compare HRUS findings with clinical examination, serological markers and conventional radiography including MRI and thus define the role of HRUS in the management of patients with SLE and identify characteristic risk factors for hand arthritis in this disease. 


\section{References}

1 Reilly PA, Evison G, McHugh NJ, Maddison PJ. Arthropathy of hands and feet in systemic lupus erythematosus. J Rheumatol 1990; 17: 777-784.

2 Alarcon-Segovia D, Abud-Mendoza C, Diaz-Jouanen E, Iglesias A. Deforming arthropathy of the hands in systemic lupus erythematosus. J Rheumatol 1988; 15: 65-69.

3 Spronk TE, Ter Borg EJ, Kallenberg CGM. Jaccoud arthropathy: a clinical subset with an increased CRP response. Ann Rheum Dis 1992; 51: $358-361$.

4 van Vugt RM, Derksen RH, Kater L, Bijlsma JW. Deforming arthropathy or lupus and rhupus hands in systemic lupus erythematosus. Ann Rheum Dis 1998; 57: 540-544.

5 van Vugt RM, Derksen RH, Kater L, Bijlsma JW. Deforming arthropathy or lupus and rhupus hands in systemic lupus erythematosus. Ann Rheum Dis 1998; 57: 540-544.

6 Ostendorf B, Scherer A, Specker C, Modder U, Schneider M. Jaccoud's arthropathy in systemic lupus erythematosus: differentiation of deforming and erosive patterns by magnetic resonance imaging. Arthritis Rheum 2003; 48: 157-165.

7 Kane D, Grassi W, Sturrock R, Balint PV. Musculoskeletal ultrasound-a state of the art review in rheumatology. Part 2: Clinical indications for musculoskeletal ultrasound in rheumatology. Rheumatology (Oxford) 2004; 43: 829-838

8 Grassi W, Cervini C. Ultrasonography in rheumatology: an evolving technique. Ann Rheum Dis 1998; 57: 268-271.

9 Iagnocco A, Ossandon A, Coari G et al. Wrist joint involvement in systemic lupus erythematosus. An ultrasonographic study. Clin Exp Rheumatol 2004; 22: 621-624.

10 Tam EM, Cohen AS, Fries JF, Masi AT, McShane DJ, Rothfield NF. The 1982 revised criteria for the classification of systemic lupus erythematosus. Arthritis Rheum 1982; 25: 1271-1277.

11 Gladman DD, Urowitz MB, Goldsmith CH, Fortin P, Ginzler E, Gordon C. The reliability of the systemic luus international collaborating

clinics/American college of rheumatology damage index in patients with systemic lupus erythematosus. Arthritis Rheum 1997; 40: 809-813.

12 Wakefield RJ, Gibbon WW, Conaghan PG et al. The value of sonography in the detection of bone erosions in patients with rheumatoid arthritis: a comparison with conventional radiography. Arthritis Rheum 2000; 43: $2762-2770$.

13 Szkudlarek M, Court-Payen M, Jacobsen S, Thomsen HS, Klarlund M, Ostergaard M. Interobserver agreement in ultrasonography of the finger and toe joints in rheumatoid arthritis. Arthritis Rheum 2003; 48 955-962.

14 Rubin JM, Adler RS, Fowlkes JB et al. Fractional moving blood volume: estimation with power Doppler US. Radiology 1995; 197 183-190.

15 Wakefield RJ, Balint P, Szkudlarek $\mathrm{M}$ et al. Proceedings from the OMERACT special interest group for musculoskeletal ultrasound including definitions for ultrasonographic pathology. J Rheumatol (in press).

16 Naredo E, Bonilla G, Gamero F, Uson J, Carmona L, Laffon A. Assessment of inflammatory activity in rheumatoid arthritis: a comparative study of clinical evaluation with grey scale and power Doppler ultrasonography. Ann Rheum Dis 2005; 64: 375-381.

17 Weidekamm C, Koller M, Weber M, Kainberger F. Diagnostic value of high-resolution B-mode and doppler sonography for imaging of hand and finger joints in rheumatoid arthritis. Arthritis Rheum 2003; 48 : 325-333.

18 Grassi W, Filippucci E, Farina A, Salaffi F, Cervini C. Ultrasonography in the evaluation of bone erosions. Ann Rheum Dis 2001; 60: 98-103.

19 Wakefield RJ, Gibbon WW, Conaghan PG et al. The value of sonography in the detection of bone erosions in patients with rheumatoid arthritis: a comparison with conventional radiography. Arthritis Rheum 2000; 43: 2762-2770.

20 Richter CM, Steiner G, Smolen JS, Isenberg DA. Erosive arthritis in systemic lupus erythematosus: analysis of a distinct clinical and serological subset. Br J Rheumatol 1998; 37: 421-424. 